\title{
Burden of Tick-Borne Encephalitis, Sweden
}

\author{
Daniel Slunge, Anders Boman, Marie Studahl ${ }^{1}$
}

In recent decades, the incidence of tick-borne encephalitis (TBE) in Sweden has increased. To calculate the burden of disease over a 17-year period, we analyzed data from the Swedish National Health Data Register for TBE cases diagnosed during 1998-2014. We compared healthcare use and sick leave associated with 2,429 persons with TBE with a referent cohort of 7,287 persons without TBE. Patients with TBE were hospitalized for significantly more days during the first year after disease onset (11.5 vs. 1.1 days), logged more specialist outpatient visits (3.6 vs. 1.2 visits), and logged more sick leave days (66 vs. 10.7 days). These differences generally increased over time. The case-fatality rate for TBE was $1.1 \%$. Our calculated cost of TBE to society provides a baseline for decisions on immunization programs. Analyzing register data, our study adds to clinical studies of smaller cohorts and model-based studies that calculate disease burden.

$\mathrm{T}$ ick-borne encephalitis virus (TBEV) is the cause of tick-borne encephalitis (TBE), an infectious disease of growing public health concern $(1,2)$. In Sweden, the disease is caused by the European subtype (TBEV-Eu), which is transmitted by the vector tick Ixodes ricinus (3). Over the past 3 decades, the number of cases has dramatically increased, with an average of 391 notified cases annually during the past 5 years (2017-2021), corresponding to an incidence of 3.8 cases/100,000 population (4,5) (Figure $1)$. In certain regions of Sweden, however, the incidence among unvaccinated persons has been up to $8.5-12$ cases $/ 100,000$ population (6). In Europe, only Lithuania, Latvia, Estonia, Czechia and Slovenia report higher notification rates, on national levels, than Sweden (7). TBEV infection is mainly asymptomatic or associated with mild signs/symptoms (e.g., fever and general malaise) but may also cause neurologic signs/symptoms in persons in all age groups (8). Clinical studies show that children account for $10 \%-16 \%$ of TBE cases (9). Clinical presentation ranges from mild meningitis to severe

Author affiliations: University of Gothenburg, Gothenburg, Sweden (D. Slunge, A. Boman, M. Studahl); Region Västra Götaland, Sahlgrenska University Hospital, Gothenburg (M. Studahl)

DOI: https://doi.org/10.3201/eid2802.204324 manifestations such as meningoencephalomyelitis with a risk for respiratory insufficiency requiring ventilator support in an intensive care unit (ICU) (10-12). In Europe, $\approx 95 \%$ of case-patients with notified TBE require hospitalization (13).

Although the case-fatality rate associated with TBEV-Eu (based on previous case series in Sweden) is estimated at only $0-1.4 \%(14,15)$, neurologic sequelae are common and often long lasting. The rate of incomplete recovery severely affecting quality of life at long-term follow-up is reported to be $\approx 40 \%-46 \%(15,16)$. There is no cure for TBE, but 2 inactivated TBEV-Eu vaccines resulting in 95\%-100\% immunogenicity are available (17).

In Europe, only Austria has implemented a national universal TBE vaccination program targeting the entire population, resulting in a pronounced decrease in TBE incidence $(18,19)$. The growing incidence of TBE has stimulated discussion regarding the need for public vaccination programs in Sweden $(20,21)$ and other countries in Europe (22-24), but thorough data concerning the burden of TBE are needed to determine cost-effectiveness.

Our purpose with this study was to provide a baseline concerning the burden of TBE to enable informed decisions on immunization programs and other healthcare interventions. We analyzed the overall burden of TBE in Sweden in terms of hospitalization, specialist outpatient visits, primary care visits, and sick leave, on the basis of register data on TBE case-patients and a matched cohort. For TBE case-patients, we also included the cost of death. The study was approved by the Regional Ethical Review Board in Gothenburg (no. 141-16).

\section{Materials and Methods}

\section{Data Sources}

We collected data from various sources and periods (Figure 2). We obtained data from the Swedish National Patient Register (provided by the National Board of Health and Welfare, https://www. socialstyrelsen.se) related to the diagnosis code for TBE (A84, International Classification of Diseases 


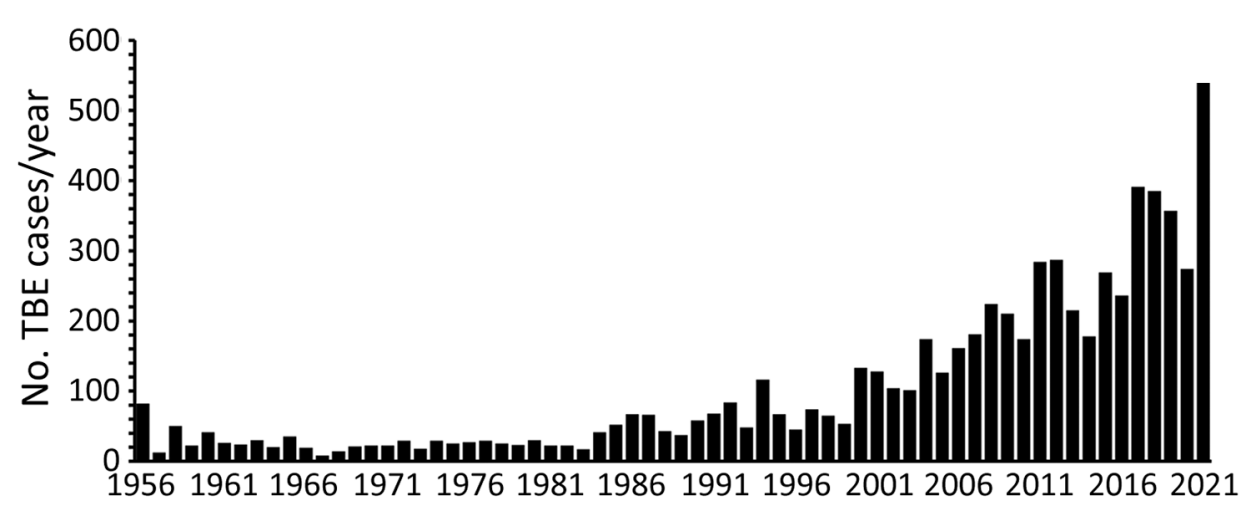

Figure 1. Reported tick-borne encephalitis cases per year, Sweden, 1956-2021. Tick-borne encephalitis became a notifiable disease in Sweden in July 2004; thus, the number of reported cases before 2005 is less certain than the number of cases from 2005 on. Source: Swedish Public Health Agency (https://www. folkhalsomyndigheten.se), 2022.

10th revision [ICD-10]), including date of notification of TBE, among patients who received inpatient care or specialist outpatient care for this diagnosis during 1998-2014. This register includes patients for whom TBE was a primary cause for hospitalization and patients ill with TBE but for whom a different primary diagnosis was the cause for hospitalization. Including both primary and nonprimary diagnoses of TBE in the data ensures that no hospitalized TBE patients are omitted. Statistics Sweden (https:/ / www.scb.se) created a matched referent cohort encompassing 3 referent persons per TBE case-patient, on the basis of sex, age in 2014, and county of residence.

The Swedish Social Insurance Agency (https:// www.forsakringskassan.se) provided data concerning numbers of sick leave days and amount of sick leave compensation during the study period for the TBE case-patients and the referent cohort. By law, the Swedish social system covers all residents 16-64 years of age and grants economic security when the ability to work is limited by $\geq 25 \%$ because of sickness, disability, or injury (25). Statistics Sweden provided the social security numbers of the referent cohort to the National Board of Health and Welfare, which provided the same information for the referent cohort as for the TBE casepatient group.

We obtained data from the Region Västra Götaland Primary Healthcare Register (https://www. vgregion.se) regarding primary care visits for persons with TBE and those in the matched cohort living in this region (1.7 million of 10 million inhabitants in Sweden). Data encompassed 5 years before through 5 years after TBE diagnosis.

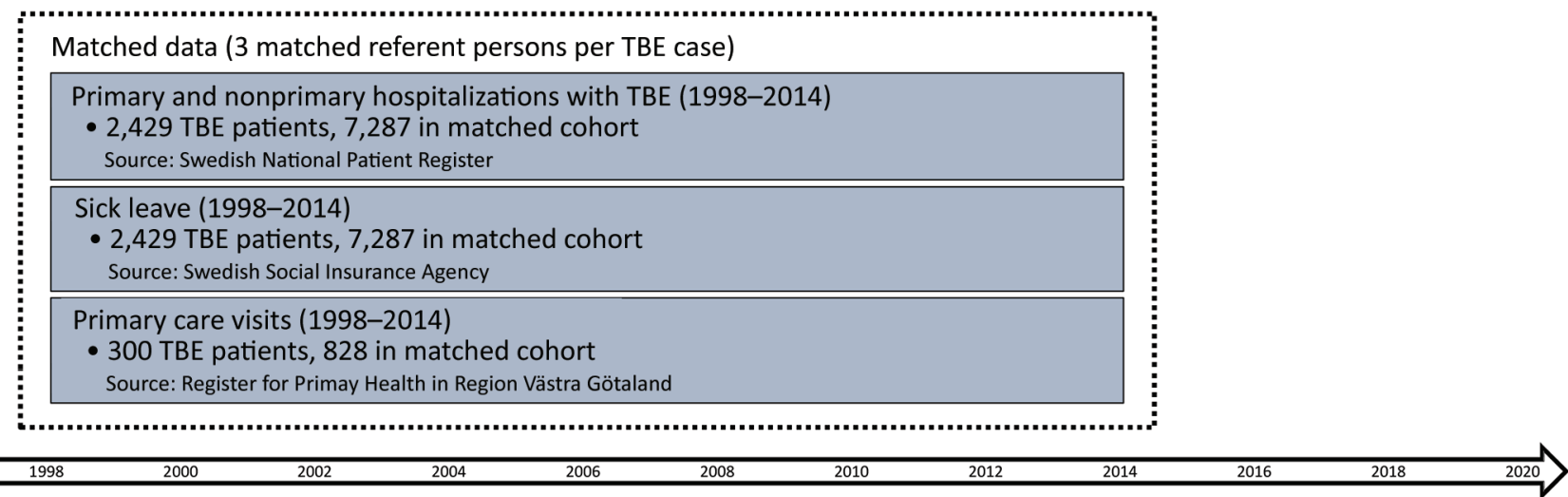

Nonmatched data

Number of notified TBE cases (2005-2019)

Source: Public Health Agency of Sweden

TBE case-fatality rate (2005-2019)

Source: Swedish National Cause of Death Register

Figure 2. Sources and periods of matched and nonmatched data used in study of tick-borne encephalitis, Sweden. Swedish National Patient Register, https://www.socialstyrelsen.se; Swedish Social Insurance Agency, https://www.forsakringskassan.se; Register for Primary Health in Region Vastra Gotaland, https://www.vgregion.se; Public Health Agency of Sweden, https://www. folkhalsomyndigheten.se; Swedish National Cause of Death Register, https://www.socialstyrelsen.se. 
TBE has been a notifiable disease in Sweden since July 1, 2004. The involved microbiology laboratories and the attending physicians are responsible for notifications to authorities. We obtained data on notified cases from the Public Health Agency (https://www. folkhalsomyndigheten.se) ) for 2005-2019, including date of reported TBE diagnosis.

Data concerning death caused by TBE (ICD-10 code A84) were obtained from the Swedish National Cause of Death Register (https://www.socialstyrelsen.se), which covers $\approx 98 \%$ of deaths in Sweden. We calculated the case-fatality rate for 2005-2019, after TBE had become a notifiable disease in Sweden, and expressed it as a ratio between the number of deceased persons divided by the number of notified TBE cases in the register maintained by the Public Health Agency of Sweden.

\section{Data Analyses}

We calculated TBE-related sick leave and healthcare consumption by analyzing the number of days of sick leave and hospitalization as well as primary care and specialist outpatient visits during years 1, 3, and 5 after TBE diagnosis, after which we compared the data with that from the referent cohort. By comparing these differences with the differences in healthcare use and sick leave days over the 3-year period before date of TBE onset, we segregated the effects exclusively caused by TBE from other potential differences between the TBE case-patients and the referent cohort. We used $t$-tests to determine whether differences between the TBE case-patients and the referent cohort were statistically significant. To account for potential sick leave days and healthcare visits resulting from TBEV infection before diagnosis, we defined the date of TBE onset as occurring 31 days before the TBE diagnosis (ICD-10 code A84) was made. Febrile TBEV-related illness precedes onset of encephalitis in the biphasic course of disease, which occurs in most patients. The duration of this febrile phase is usually $\approx 5$ days (range 2-10 days), which is then followed by a symptom-free interval of $\approx 7$ days (range 1-21 days) before onset of the actual TBE symptoms that prompt contact with either outpatient or inpatient care (8). Hence, we chose 31 days to encompass the maximum number of days of illness relating to TBE before diagnosis.

We established the date of diagnosis as the first date when a diagnosis of TBE (ICD-10 code A84) was made in either outpatient specialist or inpatient care. This date was chosen because there may be a delay of weeks to months before the Public Health Agency is notified after hospitalization and because the date on which the TBE diagnosis is entered in the Swedish National Patient Register usually corresponds to the date of hospital discharge.

We calculated the burden of TBE for each outcome from the differences in mean values between TBE case-patients and the referent cohort, while also taking into account differences in the baseline values 3 years before TBE onset.

We calculated the cost of illness for all TBE patients in Sweden by using the following monetary values, based on the burden of disease estimates. The average cost per day of hospital stay during 2014-2018 was calculated to be $€ 1,049$, and the cost per specialist outpatient visit was $€ 338$, based on the cost per patient database from the Swedish Association of Local Authorities and Regions (26). The average cost per primary care visit was calculated to be $€ 164$, based on 2019 prices charged for a physician visit in Västra Götaland (27). The average cost per day of sick leave was calculated to be $€ 199$, based on loss of income and calculated by using the 2018 median monthly wage $(€ 3,090)$ plus mandatory employer social security contributions in Sweden $(36 \%$ of the wage), divided by the number of working days in that year $(253$ days) $(28,29)$. For the purposes of this study, we counted 2 half days of sick leave as 1 full day. The cost of death caused by TBE was calculated to be $€ 4.05$ million, based on the value of a statistical life used by the Swedish Transport Administration (30). For all calculations, we used the following exchange rate: $€ 1$ equals 10 Swedish krona (SEK) ( $€ 1$ is approximately equal to US \$1.20). Statistical analyses were performed by using STATA version 16 (https:/ / www.stata.com).

\section{Results}

TBE Diagnosis in the Swedish National Patient Register Data obtained from the Swedish National Patient Register identified 2,429 reported patients hospitalized with TBE ICD-10 diagnosis code A84 during 1998-2014. Of these, 1,751 case-patients were entered in the register during 2005-2014. Over that same period, 2,047 TBE case-patients were reported in Sweden, indicating that $296(14 \%)$ such case-patients did not require hospitalization. Of the 2,429 case-patients entered in the register, 995 (41\%) were women and $1,434(59 \%)$ men.

Mean age of the 2,429 TBE case-patients entered in the National Patient Register was 47 years (47.8 for women and 46.4 for men). Comparing the age distribution of TBE cases with the general population shows that hospitalization for TBE is skewed to- 


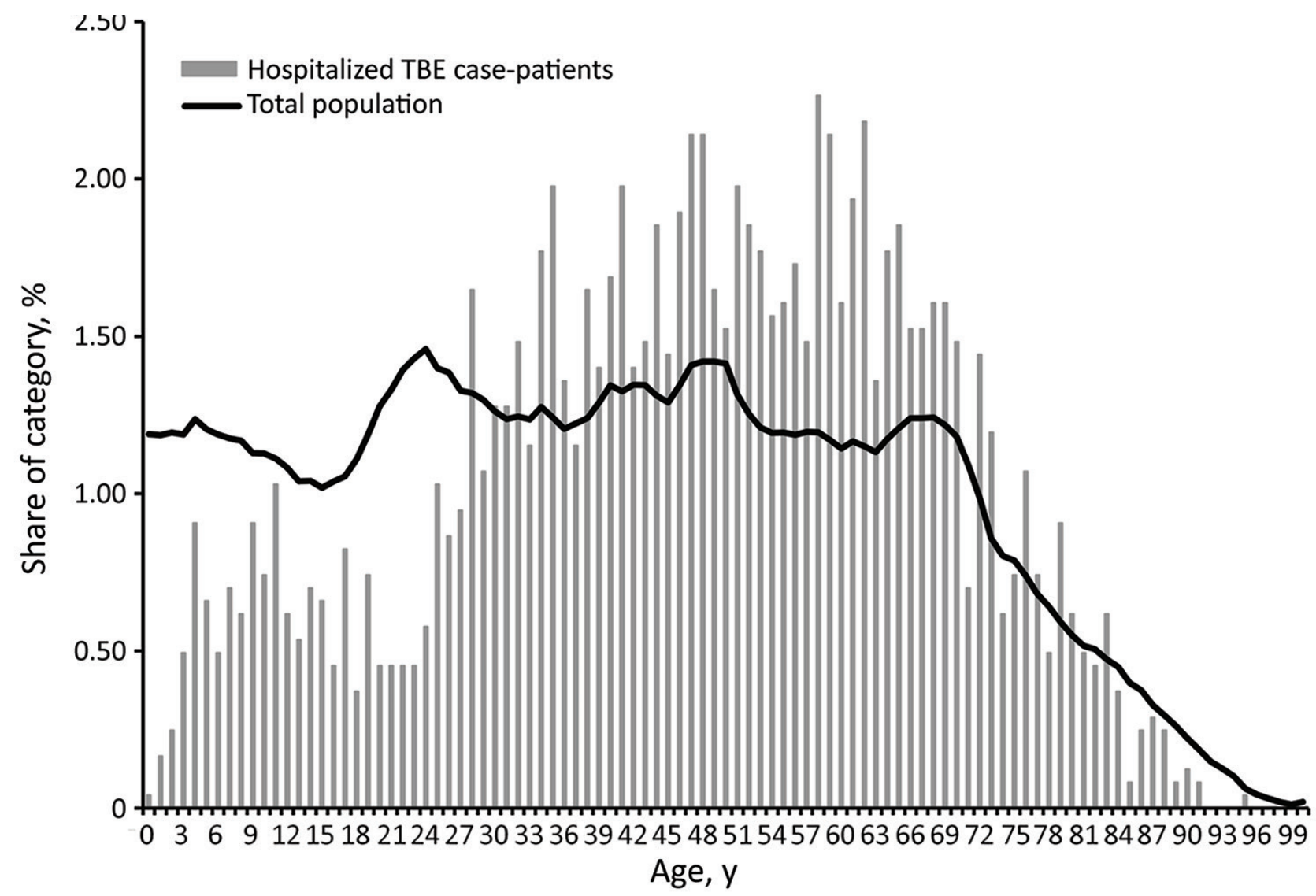

Figure 3. Percentage of hospitalized tick-borne encephalitis case-patients, by age, during 1998-2014 and percentage of population of Sweden in 2014 , by age.

ward a higher mean age than the population at large (Figure 3).

\section{Death from TBE}

A total of 39 TBE-related deaths were entered in the Swedish National Cause of Death Register during 2005-2019. During the same period, 3,681 TBE cases were reported to the Public Health Agency of Sweden, corresponding to a case-fatality rate of $1.1 \%$. In all, $25(64 \%)$ of the deceased patients were men and 14 (36\%) were women; 35 (90\%) of deceased patients were $\geq 60$ years of age.

\section{Days of Inpatient Care and Number of Specialist Outpatient Visits}

When we compared the burden of TBE in terms of healthcare use between TBE case-patients and the referent cohort at 3 years before and 1,3 and 5 years after TBE onset date, we found that before TBE onset, differences in the average number of days spent in hospital care were small and statistically insignificant; however, after TBE onset, TBE casepatients spent significantly longer than the referent cohort in hospital care (Table 1). During the first year after TBE onset, case-patients were hospitalized an average of 11.5 days, compared with an average of 1.1 days for the referent cohort. These differences remained largely unchanged in the following years.

Within the 3-year period before date of TBE onset, the average number of specialist outpatient visits was slightly higher among patients with a TBE diagnosis than among the referent cohort (Table 1). By 1 year after date of onset of TBE, these differences became much more pronounced and grew over time; after 5 years, the average difference was almost 4 visits.

\section{Sick Leave Days}

Compared with the referent cohort, patients with TBE spent an average of 12 days more on sick leave over the 3-year period before TBE onset (Table 1). One year after TBE onset, this difference increased significantly; those with TBE spent an average of 66 days on sick leave, compared with 11 days for the referent cohort. Three years after TBE onset, this 
Table 1. Healthcare use and sick leave days for persons with TBE and the matched referent cohort, Sweden, 1998-2014*

\begin{tabular}{|c|c|c|c|c|}
\hline \multirow[b]{2}{*}{ Variable } & \multirow[b]{2}{*}{ Within 3 y before TBE } & \multicolumn{3}{|c|}{ After TBE } \\
\hline & & Within $1 \mathrm{y}$ & Within $3 y$ & Within $5 y$ \\
\hline \multicolumn{5}{|l|}{ Days hospitalized } \\
\hline Case cohort, mean (no.) & $1.35(2,228)$ & $11.50(2,274)$ & $12.73(1,863)$ & $14.69(1,466)$ \\
\hline Referent cohort, mean (no.) & $2.07(6,684)$ & $1.12(6,822)$ & $3.27(5,589)$ & $5.64(4,404)$ \\
\hline Difference in means & 0.28 & $10.38 \dagger$ & $9.46 \dagger$ & $9.05+$ \\
\hline \multicolumn{5}{|l|}{ Specialist outpatient visits } \\
\hline Case cohort, mean (no.) & $3.92(2,228)$ & $3.65(2,270)$ & $6.78(1,863)$ & $9.45(1,466)$ \\
\hline Referent cohort, mean (no.) & $3.31(6,684)$ & $1.22(6,810)$ & $3.53(5,583)$ & $5.74(4,398)$ \\
\hline Difference in means & $0.62 \dagger$ & $2.42 \dagger$ & $3.25 \dagger$ & $3.71 \dagger$ \\
\hline \multicolumn{5}{|l|}{ Days of sick leave } \\
\hline Case cohort, mean (no.) & $63.3(1406)$ & $66.0(1,434)$ & $122.6(1,169)$ & $144.0(902)$ \\
\hline Referent cohort, mean (no.) & $51.4(2765)$ & $10.7(2,802)$ & $45.9(2,286)$ & $78.1(1,793)$ \\
\hline Difference in means & $11.82 \ddagger$ & $55.32 \dagger$ & $76.66 \dagger$ & $65.85 \dagger$ \\
\hline \multicolumn{5}{|l|}{ Primary healthcare visits } \\
\hline Case cohort, mean (no.) & $9.19(280)$ & $6.44(276)$ & $14.43(228)$ & $23.29(175)$ \\
\hline Referent cohort, mean (no.) & 10.55 (779) & $3.90(763)$ & $11.54(638)$ & $19.55(502)$ \\
\hline Difference in means & -1.36 & $2.54 \dagger$ & $2.89 \S$ & 3.74 \\
\hline $\begin{array}{l}{ }^{*} \text { TBE, tick-borne encephalitis. } \\
\text { †Significance at the } 1 \% \text { level. } \\
\text { †Significance at the } 5 \% \text { level. } \\
\S \text { Significance at the } 10 \% \text { level. }\end{array}$ & & & & \\
\hline
\end{tabular}

difference was even greater but decreased again; after 5 years, it returned to the same level as 1 year after the onset of TBE.

\section{Primary Care Visits}

The number of primary care visits during the 3 years before TBE onset did not differ significantly between the 2 groups (Table 1). However, in the first year after TBE onset, the number of visits was substantially higher for those with a TBE diagnosis. This difference declined over time, and after 3 years there were no statistically significant differences.

\section{Burden of TBE and Cost of Illness}

Calculations of the burden of TBE in terms of healthcare use and sick leave and the associated cost of illness per TBE case 1, 3 and 5 years after TBE onset take into account the differences between the TBE case-patients and referent cohort within the 3-year period before date of TBE onset (Table 2). The average cost of illness for $1 \mathrm{TBE}$ case-patient was $\approx € 20,504$ during the first year after TBE onset. Days spent in hospital accounted for $52 \%$ of this cost; days on sick leave, $42 \%$. Specialist and primary care visits accounted for 3\% each. The cost grew by $\approx € 3,600$ in years 2 and 3 to a cumulative cost of $€ 24,126$ by 3 years after TBE onset. During years $4-5$, the per patient cost decreased by about $€ 2,300$ to a cumulative cost of $€ 21,834 / \mathrm{TBE}$ case 5 years after TBE onset. Over time, the share of costs for inpatient care decreased to $41 \%$, and the costs associated with sick leave increased to $49 \%$ at 5 years after TBE onset. The share of costs for specialist visits increased only slightly to $5 \%$ and for primary care visits to $4 \%$.

Of the 359 TBE cases registered in Sweden in 2019, a total of 4 case-patients died of this disease, equating to a cost of illness of $€ 7.3$ million and a cost of death of $€ 16.2$ million, for a total cost of $€ 23.5$ million (Table 3). The corresponding average annual cost for 2015-2019 is $€ 24.5$ million; the cost of illness accounts for $€ 6.6$ million and that of death $€ 17.8$ million.

\section{Discussion}

The burden of tick-borne encephalitis was higher than previously estimated. This study, based on register data in Sweden, where underreporting of TBE is demonstrably low (31), shows that TBE poses a

\begin{tabular}{|c|c|c|c|c|c|c|c|c|c|}
\hline \multirow[b]{2}{*}{ Variable } & \multicolumn{3}{|c|}{ Within $1 \mathrm{y}$ after TBE onset } & \multicolumn{3}{|c|}{ Within 3 y after TBE onset } & \multicolumn{3}{|c|}{ Within 5 y after TBE onset } \\
\hline & $\begin{array}{c}\text { Healthcare } \\
\text { use and } \\
\text { sick leave, } \\
\text { no. }\end{array}$ & $\begin{array}{l}\text { Cost of } \\
\text { illness/ } \\
\text { case, } €\end{array}$ & $\begin{array}{c}\text { Share of } \\
\text { total cost } \\
\text { of illness, } \\
\%\end{array}$ & $\begin{array}{c}\text { Healthcare } \\
\text { use and } \\
\text { sick leave, } \\
\text { no. }\end{array}$ & $\begin{array}{l}\text { Cost of } \\
\text { illness/ } \\
\text { case, } €\end{array}$ & $\begin{array}{c}\text { Share of } \\
\text { total cost } \\
\text { of illness, } \\
\%\end{array}$ & $\begin{array}{c}\text { Healthcare } \\
\text { use and } \\
\text { sick leave, } \\
\text { no. }\end{array}$ & $\begin{array}{l}\text { Cost of } \\
\text { illness/ } \\
\text { case, } €\end{array}$ & $\begin{array}{c}\text { Share of } \\
\text { total cost } \\
\text { of illness, } \\
\%\end{array}$ \\
\hline Days hospitalized & 10.10 & 10,599 & 51.7 & 9.19 & 9,638 & 39.9 & 8.77 & 9,203 & 41.2 \\
\hline Specialist outpatient visits & 1.80 & 610 & 3.0 & 2.63 & 890 & 3.7 & 3.09 & 1,045 & 4.8 \\
\hline Primary care visits & 3.90 & 639 & 3.1 & 4.25 & 696 & 2.9 & 5.10 & 836 & 3.8 \\
\hline Days of sick leave & 43.50 & 8,656 & 42.2 & 64.80 & 12,902 & 53.5 & 54.00 & 10,750 & 49.2 \\
\hline Total & NA & 20,504 & NA & NA & 24,126 & NA & NA & 21,834 & NA \\
\hline
\end{tabular}

${ }^{*}$ Calculations account for differences between TBE case-patients and referent cohort during a 3-y period before date of disease onset. NA, not applicable; TBE, tick-borne encephalitis. 
Table 3. Cost of illness and death from TBE in Sweden in 2019 and per year 2015-2019*

\begin{tabular}{lcc}
\hline Variable & 2019 & $2015-2019$, average yearly cost \\
\hline Registered TBE cases, no. & 359 & 1,641 \\
Deaths caused by TBE, no. & 4 & 22 \\
Cost of illness, $€$ & $7,279,054 \dagger$ & $6,639,317 \dagger$ \\
Cost of death, $€$ & $16,200,000 \dagger \dagger$ & $17,820,000+\dagger$ \\
Total cost of illness and death, $€$ & $23,479,054$ & $24,459,317$ \\
\hline
\end{tabular}

*TBE, tick-borne encephalitis.

$†$ No. registered TBE cases minus the number of deaths caused by TBE times the cost of illness per TBE case within 1 y after TBE onset (€20,504). $\dagger+$ No. deaths caused by TBE times the value of a statistical life in Sweden (€4.05 million).

substantial burden as measured by use of healthcare and sick leave.

The average of 11.5 days of hospitalization during the first year after TBE onset found in this study is similar to the 12 days found in a register-based study in Latvia, which covered $\approx 2,000$ TBE cases (32). Our figures fall between findings of smaller studies from Slovenia (9 days) (33) and Germany (18 days) (10). By comparison, an earlier study in Sweden found that herpes simplex encephalitis, one of the most severe viral encephalitides, required an average of 55 days of hospitalization (34). Not surprisingly, the same pattern was observed in a recent US study quantifying the health economic effects of viral encephalitis, which found that patients with herpes simplex encephalitis were associated with longer cumulative hospital stays than were patients with all other viral encephalitides (35). However, comparisons between TBE and other viral encephalitides are complicated by differences in severity and prognosis.

According to our analysis, hospitalization accounted for only about half of the disease burden from TBE but sick leave days accounted for a substantial share. We found a difference in sick leave days taken before the onset of TBE, and those who received a TBE diagnosis took more sick leave days on average. We see no obvious explanation for this difference. Among those with TBE, sick leave days increased sharply over the first 3 years after TBE onset. In the 4-5 years after TBE onset, patients with this illness instead took fewer sick leave days on average than the referent cohort. This finding may be associated with rules regarding the maximum number of sick leave days allowed, but the register data on which this study was based did not permit further analysis.

This pattern of sick leave for TBE differs somewhat from that for another tickborne disease, neuroborreliosis, which was investigated through a register study in Denmark that showed that more days were taken for sick leave during the first year but tapered rapidly thereafter (36). In that study, 2 years after diagnosis the number of sick leave days did not differ substantially between neuroborreliosis casepatients and controls. The differences in sick leave pattern between these 2 diseases probably reflect the moderate to severe sequelae of TBE in up to one half of case-patients at long-term follow-up, compared with neuroborreliosis, for which only $12 \%$ experienced sequelae that affected their activities of daily living $(15,16,37)$.

The TBE case-fatality rate calculated in this study $(1.1 \%)$, based on register data from a 15-year period, is considerably higher than that reported for Sweden during the historical period 1956-1989 (0.5\%) (38) and among the average notified cases from 23 countries in Europe during 2012-2016 (0.5\%) (13). However, in smaller cohorts from different parts of Europe, fatality rates vary from $0.75 \%$ to $3.6 \%(16,39)$. Fatality rates may vary according to several factors, including virus virulence, sensitivities of different surveillance systems, variations in how death is recorded in different countries, demographics (e.g., age), and immunosuppression; the latter 2 factors are known to increase severity and death (39-43).

As in previous studies $(10,16,22)$, we found that TBE affects more men than women, probably because compared with men, women are more likely to use protective measures, appreciate the risk, and be more knowledgeable about tickborne diseases (44-46). Moreover, the mortality rate was somewhat higher among men than women.

Translating the societal burden of TBE that arises from increased healthcare use and sick leave into monetary cost of illness is helpful for assessing the costeffectiveness of immunization programs and other healthcare interventions. The average cost of hospitalization and specialist outpatient visits during the first year after TBE diagnosis, derived from this study, is of the same order of magnitude as earlier estimates used in models to calculate the cost-effectiveness of TBE immunization programs (21). However, we found that it is also essential to include the substantial cost of illness related to sick leave when comparing costs and benefits of TBE immunization programs. Excluding sick leave-related costs from such analysis would underestimate the cost of illness, especially after the year of incidence, because the percentage of costs associated with sick leave increases over time. 
Using a referent cohort comparison in this study made it possible to identify the net burden of disease through analysis of the differences between the 2 groups before and after TBE onset. Including the costs of healthcare use and sick leave of only the TBE case-patients would overestimate the cost of illness.

The proportion of TBE case-patients requiring intensive care could not be reliably identified from the registers, which poses a study limitation. However, ICU stays are probably associated with a large part of hospitalization costs, as shown in a large US study of $>25,000$ adult patients with meningitis and encephalitis (47). One of few studies to include the need for intensive care over the course of TBE showed that $12 \%$ of 656 TBE patients in Germany received treatment in an ICU for an average of 12 days (10). Another study of $448 \mathrm{TBE}$ patients in Slovenia showed that $7 \%$ received treatment in ICUs (33). Assuming that $10 \%$ of the TBE patients in our study received treatment in an ICU for an average of 12 days, at an average cost of $€ 6,500$ per day (48), the estimated cost of hospitalization 1 year after TBE onset would increase by $62 \%$ to $€ 17,140$ per case and the total cost of illness for the 359 TBE cases in Sweden in 2019 by $32 \%$ to $€ 9.6$ million.

Another study limitation is that our burden of disease calculations did not take into account less-tangible costs, such as the pain and suffering associated with long-term sequelae commonly associated with TBE or changes in recreational behavior motivated by the increased risk for TBE (49). The short time perspective of the study is also a limitation because it only analyzes healthcare use and sick leave for 5 years after TBE onset. Some studies do address longterm effects (50), but these need to be complemented by additional studies that take into account the costs associated with the long-term sequelae of TBE.

By analyzing data from the Swedish National Patient Register, our findings add to clinical studies of smaller cohorts $(10,15)$ and to model-based studies that calculate disease burden (21-23). Such studies are of value to patient care with regard to detecting cognitive and neurologic impairments, and they provide an estimate of the frequency, nature, and severity of sequelae. Register data relating to healthcare use, sick leave, and death provide a broader base of knowledge concerning the burden of TBE. The calculated cost of illness per TBE case in this study provides a baseline for analyses of cost-effectiveness of immunization programs, which frequently rely on cost data from other diseases to estimate costs for hospitalization and specialist outpatient visits in subsequent years.

\section{Acknowledgments}

We are grateful for the funding provided by the Swedish Government under the ALF agreement (grant no. 74050) of Sahlgrenska Academy at the University of Gothenburg and Stiftelsen Längmanska Kulturfonden.

\section{About the Author}

Dr. Slunge is a researcher in health and environmental economics at the Environment for Development Initiative at the University of Gothenburg. His research focuses on risk perception and behavior in relation to environmental health threats.

\section{References}

1. Pierson TC, Diamond MS. The continued threat of emerging flaviviruses. Nat Microbiol. 2020;5:796-812. https:/ / doi.org/10.1038/s41564-020-0714-0

2. Kunze U. The International Scientific Working Group on Tick-Borne Encephalitis (ISW TBE): review of 17 years of activity and commitment. Ticks Tick Borne Dis. 2016;7:399_ 404. https:// doi.org/10.1016/j.ttbdis.2015.12.018

3. Haglund M, Vene S, Forsgren M, Günther G, Johansson B, Niedrig M, et al. Characterisation of human tick-borne encephalitis virus from Sweden. J Med Virol. 2003;71:610-21. https:// doi.org/10.1002/jmv.10497

4. Jaenson TGT, Hjertqvist M, Bergström T, Lundkvist A. Why is tick-borne encephalitis increasing? A review of the key factors causing the increasing incidence of human TBE in Sweden. Parasit Vectors. 2012;5:184. https:/ / doi.org/ 10.1186/1756-3305-5-184

5. Public Health Agency of Sweden. Tick-borne encephalitis [in Swedish] [cited 2022 Jan 18.] https://www.folkhalsomyndigheten.se/folkhalsorapportering-statistik/ statistik-a-o/sjukdomsstatistik/tick-borne-encephalitistbe/?t=county

6. Askling $\mathrm{HH}$, Insulander M, Hergens MP, Leval A. Tick borne encephalitis (TBE)-vaccination coverage and analysis of variables associated with vaccination, Sweden. Vaccine. 2015;33:4962-8. https:/ / doi.org/10.1016/ j.vaccine.2015.07.030Euro

7. European Centre for Disease Prevention and Control. Tick-borne encephalitis. Annual epidemiological report for 2019. Stockholm: The Centre; 2021.

8. Lindquist L, Vapalahti O. Tick-borne encephalitis. Lancet. 2008;371:1861-71. https:// doi.org/10.1016/ S0140-6736(08)60800-4

9. Steffen R. Tick-borne encephalitis (TBE) in children in Europe: epidemiology, clinical outcome and comparison of vaccination recommendations. Ticks Tick Borne Dis. 2019;10:100-10. https://doi.org/10.1016/j.ttbdis.2018.08.003

10. Kaiser R. The clinical and epidemiological profile of tick-borne encephalitis in southern Germany 1994-98: a prospective study of 656 patients. Brain. 1999;122:2067-78. https:/ / doi.org/10.1093/brain/122.11.2067

11. Zambito Marsala S, Pistacchi M, Gioulis M, Mel R, Marchini C, Francavilla E. Neurological complications of tick borne encephalitis: the experience of 89 patients studied and literature review. Neurol Sci. 2014;35:15-21. https://doi.org/10.1007/s10072-013-1565-8

12. Bogovič P, Stupica D, Rojko T, Lotrič-Furlan S, Avšič-Županc T, Kastrin A, et al. The long-term outcome 
of tick-borne encephalitis in central Europe. Ticks Tick Borne Dis. 2018;9:369-78. https://doi.org/10.1016/ j.ttbdis.2017.12.001

13. Beauté J, Spiteri G, Warns-Petit E, Zeller H. Tick-borne encephalitis in Europe, 2012 to 2016. Euro Surveill. 2018;23:1800201. https:/ / doi.org/10.2807/1560-7917. ES.2018.23.45.1800201

14. Haglund M, Forsgren M, Lindh G, Lindquist L. A 10-year follow-up study of tick-borne encephalitis in the Stockholm area and a review of the literature: need for a vaccination strategy. Scand J Infect Dis. 1996;28:217-24. https:/ / doi.org/ $10.3109 / 00365549609027160$

15. Günther G, Haglund M, Lindquist L, Forsgren M, Sköldenberg B. Tick-bone encephalitis in Sweden in relation to aseptic meningo-encephalitis of other etiology: a prospective study of clinical course and outcome. J Neurol. 1997;244:230-8. https:// doi.org/10.1007/s004150050077

16. Mickiene A, Laiskonis A, Günther G, Vene S, Lundkvist A, Lindquist L. Tickborne encephalitis in an area of high endemicity in Lithuania: disease severity and long-term prognosis. Clin Infect Dis. 2002;35:650-8. https:/ / doi.org/ 10.1086/342059

17. Loew-Baselli A, Konior R, Pavlova BG, Fritsch S, Poellabauer E, Maritsch F, et al.; FSME-IMMUN study group. Safety and immunogenicity of the modified adult tick-borne encephalitis vaccine FSME-IMMUN: results of two large phase 3 clinical studies. Vaccine. 2006;24:5256-63. https://doi.org/10.1016/j.vaccine.2006.03.061

18. Heinz FX, Stiasny K, Holzmann H, Grgic-Vitek M, Kriz B, Essl A, et al. Vaccination and tick-borne encephalitis, central Europe. Emerg Infect Dis. 2013;19:69-76. https:/ / doi.org/10.3201/eid1901.120458

19. Kollaritsch H, Paulke-Korinek M, Holzmann H, Hombach J, Bjorvatn B, Barrett A. Vaccines and vaccination against tick-borne encephalitis. Expert Rev Vaccines. 2012;11:110319. https://doi.org/10.1586/erv.12.86

20. Slunge $D$. The willingness to pay for vaccination against tick-borne encephalitis and implications for public health policy: evidence from Sweden. PLoS One. 2015;10:e0143875. https://doi.org/10.1371/journal.pone.0143875

21. Shedrawy J, Henriksson M, Hergens MP, Askling HH. Estimating costs and health outcomes of publicly funded tick-born encephalitis vaccination: a cost-effectiveness analysis. Vaccine. 2018;36:7659-65. https://doi.org/ 10.1016/j.vaccine.2018.10.086

22. Fafangel M, Cassini A, Colzani E, Klavs I, Grgič Vitek M, Učakar V, et al. Estimating the annual burden of tick-borne encephalitis to inform vaccination policy, Slovenia, 2009 to 2013. Euro Surveill. 2017;22:30509. https://doi.org/10.2807/1560-7917.ES.2017.22.16.30509

23. Šmit R, Postma MJ. The burden of tick-borne encephalitis in disability-adjusted life years (DALYs) for Slovenia. PLoS One. 2015;10:e0144988. https://doi.org/10.1371/journal. pone. 0144988

24. Zavadska D, Anca I, André F, Bakir M, Chlibek R, Cižman M, et al. Recommendations for tick-borne encephalitis vaccination from the Central European Vaccination Awareness Group (CEVAG). Hum Vaccin Immunother. 2013;9:362-74. https:// doi.org/10.4161/hv.22766

25. Borg K, Goine H, Söderberg E, Marnetoft SU, Alexanderson K. Comparison of seven measures of sickness absence based on data from three counties in Sweden. Work. 2006;26:421-8.

26. Swedish Association of Local Authorities and Regions. Cost per patient database [in Swedish] [cited 2020 Oct 7]. https://skr.se/skr/halsasjukvard/ekonomiavgifter/ kostnadperpatientkpp/kppdatabas.46722.html
27. Region Västra Götaland. List of prices for medical interventions [in Swedish] [cited 2020 Oct 7].

https://alfresco.vgregion.se/alfresco/service/vgr/storage/ node/content/workspace/SpacesStore/c057c2eb-8e34460d-82b4-b947d7615858/Utoml\%c3\%a4nsprislista\%202019\%20 version \%202019-02-20.pdf?a=false\&guest=true

28. Statistics Sweden. Median income 2018 [cited 2019 Dec 12]. https://www.scb.se/en/ http://www.statistikdatabasen. scb.se/pxweb/sv/ssd/START_HE_HE0110_HE0110A/ NetInk02

29. Swedish Tax Agency. Number of working days 2018 [in Swedish] [cited 2019 Dec 12]. https:/ / www.skatteverket.se/ privat/skatter.4.6a6688231259309ff1f800029074.html

30. The Swedish Transport Administration. Method of analysis and socio-economic values for the transport sector: ASEK 6.1 [in Swedish] [cited 2019 Dec 12]. http:/ / xn--svrdsj-cua2m. se/wp-content/uploads/2018/12/09_trafiksakerhet_a61.pdf

31. Haglund M, Settergren B, Heinz FX, Günther G; ISW-TBE Study Group. Report of the Meningitis Program of the International Scientific Working Group on TBE. Serological screening of patients with viral CNS-infection of unknown etiology in search of undiagnosed TBE cases. Vaccine. 2003;21(Suppl 1):S66-72. https:/ / doi.org/10.1016/ S0264-410X(02)00816-2

32. Zavadska D, Odzelevica Z, Karelis G, Liepina L, Litauniece ZA, Bormane A, et al. Tick-borne encephalitis: a 43-year summary of epidemiological and clinical data from Latvia (1973 to 2016). PLoS One. 2018;13:e0204844. https:/ / doi.org/10.1371/journal.pone.0204844

33. Logar M, Bogovič P, Cerar D, Avsic-Zupanc T, Strle F. Tick-borne encephalitis in Slovenia from 2000 to 2004: comparison of the course in adult and elderly patients. Wien Klin Wochenschr. 2006;118:702-7. https:/ / doi.org/ 10.1007/s00508-006-0699-6

34. Hjalmarsson A, Blomqvist P, Sköldenberg B. Herpes simplex encephalitis in Sweden, 1990-2001: incidence, morbidity, and mortality. Clin Infect Dis. 2007;45:875-80. https://doi.org/10.1086/521262

35. Kiyani M, Liu B, Charalambous LT, Adil SM, Hodges SE, Yang S, et al. The longitudinal health economic impact of viral encephalitis in the United States. J Med Microbiol. 2020;69:270-9. https:// doi.org/10.1099/jmm.0.001153

36. Obel N, Dessau RB, Krogfelt KA, Bodilsen J, Andersen NS, Møller JK, et al. Long term survival, health, social functioning, and education in patients with European Lyme neuroborreliosis: nationwide population based cohort study. BMJ. 2018;361:k1998. https://doi.org/10.1136/bmj.k1998

37. Berglund J, Stjernberg L, Ornstein K, Tykesson-Joelsson K, Walter H. 5-y Follow-up study of patients with neuroborreliosis. Scand J Infect Dis. 2002;34:421-5. https://doi.org/10.1080/00365540110080421

38. Holmgren EB, Forsgren M. Epidemiology of tick-borne encephalitis in Sweden 1956-1989: a study of 1116 cases. Scand J Infect Dis. 1990;22:287-95. https:/ / doi.org/ 10.3109/00365549009027050

39. Lenhard T, Ott D, Jakob NJ, Pham M, Bäumer P, MartinezTorres F, et al. Predictors, neuroimaging characteristics and long-term outcome of severe European tick-borne encephalitis: a prospective cohort study. PLoS One. 2016; 11:e0154143. https://doi.org/10.1371/journal.pone.0154143

40. Aw D, Silva AB, Palmer DB. Immunosenescence: emerging challenges for an ageing population. Immunology. 2007;120:435-46. https:// doi.org/10.1111/j.1365-2567. 2007.02555.x

41. Czupryna P, Grygorczuk S, Krawczuk K, Pancewicz S, Zajkowska J, Dunaj J, et al. Sequelae of tick-borne 
encephalitis in retrospective analysis of 1072 patients. Epidemiol Infect. 2018;146:1663-70. https:/ / doi.org/ 10.1017/S0950268818002005

42. Knight A, Pauksens K, Nordmark G, Kumlien E. Fatal outcome of tick-borne encephalitis in two patients with rheumatic disease treated with rituximab. Rheumatology (Oxford). 2017;56:855-6. https:// doi.org/10.1093/ rheumatology/kew495

43. Lipowski D, Popiel M, Perlejewski K, Nakamura S, Bukowska-Osko I, Rzadkiewicz E, et al. A cluster of fatal tick-borne encephalitis virus infection in organ transplant setting. J Infect Dis. 2017;215:896-901. https://doi.org/ 10.1093/infdis/jix040

44. Slunge D, Boman A. Learning to live with ticks? The role of exposure and risk perceptions in protective behaviour against tick-borne diseases. PLoS One. 2018;13:e0198286. https:// doi.org/10.1371/journal.pone.0198286

45. Slunge D, Jore S, Krogfelt KA, Jepsen MT, Boman A Who is afraid of ticks and tick-borne diseases? Results from a cross-sectional survey in Scandinavia. BMC Public Health. 2019;19:1666. https://doi.org/10.1186/s12889-019-7977-5

46. Jepsen MT, Jokelainen P, Jore S, Boman A, Slunge D, Krogfelt KA. Protective practices against tick bites in Denmark, Norway and Sweden: a questionnaire-based study. BMC Public Health. 2019;19:1344. https:/ / doi.org/ 10.1186/s12889-019-7613-4

47. Balada-Llasat JM, Rosenthal N, Hasbun R, Zimmer L, Ginocchio CC, Duff S, et al. Cost of managing meningitis and encephalitis among adult patients in the United States of America. Int J Infect Dis. 2018;71:117-21. https:/ / doi.org/ 10.1016/j.ijid.2018.04.799

48. Swedish Intensive Care Register. Annual report 2018 [in Swedish] [cited 2020 Sep 10]. https:/ / www.icuregswe.org/ globalassets/arsrapporter/analyserande_arsrapport 2018.pdf

49. Slunge D, Sterner T, Adamowicz W. Valuation when baselines are changing: tick-borne disease risk and recreational choice. Resour Energy Econ. 2019;58:101119. https://doi.org/10.1016/j.reseneeco.2019.101119

50. Veje M, Nolskog P, Petzold M, Bergström T, Lindén T, Peker $Y$, et al. Tick-borne encephalitis sequelae at long-term follow-up: a self-reported case-control study. Acta Neurol Scand. 2016;134:434-41. https:/ / doi.org/10.1111/ane.12561

Address for correspondence: Daniel Slunge, Environment for Development Initiative, University of Gothenburg, PO Box 170, 40530 Gothenburg, Sweden; email: daniel.slunge@gu.se

\section{EID Podcast: \\ AMR Nontyphoidal Salmonella Infections, United States}

Among the 1.2 million cases of nontyphoidal Salmonella infections in the United States each year, only 23,000 patients are hospitalized. Although most Salmonella cases resolve on their own, patients with severe illness might require treatment with antimicrobial drugs.

But what happens when treatment doesn't work? Antimicrobial resistance among Salmonella is a growing threat, and public health officials at CDC and beyond are on a mission to curb its spread before it is too late.

In this EID podcast, Dr. Felicita Medalla, a CDC epidemiologist, investigates the rising incidence of AMR nontyphoidal Salmonella in the United States.

Visit our website to listen: https://go.usa.gov/xFZyx 